\title{
Association of simultaneously measured four-limb blood pressures with cardiovascular function: a cross-sectional study
}

\author{
Xiaorui Song ${ }^{1}$, Gaoyang Li ${ }^{1}$, Aike Qiao ${ }^{1 *}$ and Zhihui Chen ${ }^{2}$
}

\author{
*Correspondence: \\ qak@bjut.edu.cn \\ ${ }^{1}$ College of Life Science \\ and Bioengineering, Beijing \\ University of Technology, \\ No.100, Pingleyuan, \\ Chaoyang District, Beijing, \\ China \\ Full list of author information \\ is available at the end of the \\ article
}

\begin{abstract}
Background: Simultaneous measurement of four-limb blood pressures can improve the accuracy of cardiovascular disease diagnosis. This study aims to investigate the association of simultaneously measured four-limb blood pressures with cardiovascular function as the non-invasive diagnostic method of cardiovascular disease in primary care.
\end{abstract}

Methods: 229 subjects ( 62 males, mean age, $63.50 \pm 11.13$ years; 167 females, mean age, $59.47 \pm 7.33$ years) were enrolled. Four-limb blood pressure measurements were simultaneously performed using a blood pressure and pulse monitor device in the supine position. Cardiac functional parameters were also measured by using a cardiac hemodynamic detector in the same position. Data were statistically analyzed with SPSS15.0.

Results: The mean age of the 229 subjects was $60.56 \pm 8.68$ years. Cardiovascular functional parameters decreased with age and body mass index (BMI), only the total peripheral resistance (TPR) was in contrast. Age, BMI, left ankle diastolic pressure (LADP), high arm mean arterial pressure (HARMAP), left arm diastolic pressure (LARDP) and right ankle diastolic pressure (RADP) were significantly correlated with cardiovascular functional parameters. Cardiovascular functional parameters have significant differences with inter-arm difference in systolic blood pressure (SBP) between $\geq 10$ and $<10 \mathrm{mmHg}$, inter-ankle difference in SBP between $\geq 15$ and $\geq 20 \mathrm{mmHg}$, inter-ankle difference in SBP between $\geq 15$ and $<10 \mathrm{mmHg}$ and right ankle brachial index (RABI) between $\leq 0.9$ and $\geq 1.0$. After excluding 99 hypertensive patients, a part of cardiovascular functional parameters has still significant differences with inter-arm difference in SBP between $\geq 10$ and $\geq 15 \mathrm{mmHg}$ and RABI between $\leq 0.9$ and $\geq 1.0$.

Conclusion: Age, BMI, LADP, HARMAP, LARDP and RADP were the determinants of cardiovascular functional parameters. In addition, a part of cardiovascular functional parameter is associated with inter-arm difference in SBP $\geq 10 \mathrm{mmHg}$, inter-ankle difference in $\mathrm{SBP} \geq 15 \mathrm{mmHg}$ and $\mathrm{RABI} \leq 0.9$, while these differences still existed after excluding 99 hypertensive patients. Hence, simultaneous measurement of four-limb blood pressures has become feasible and useful approach to the non-invasive diagnostic method of cardiovascular disease in primary care.

Keywords: Cardiovascular function, Four limbs, Blood pressure difference, Simultaneous measurement 


\section{Background}

Accurate measurement of blood pressure and scientific evaluation are the precondition for the early detection of cardiovascular disease. The studies found that four-limb blood pressure simultaneous measurement can improve the accuracy of blood pressure for cardiovascular disease diagnosis [1-3]. Therefore, it is an important that four-limb blood pressure should be simultaneously measured to identify and manage the cardiovascular disease. However, most evidences on cardiovascular disease from these studies are obtained by either measuring single limb blood pressure or performing sequence measurement instead of simultaneous four limbs measurement [4-6]. Current technology has allowed to measure four-limb blood pressure simultaneously [7], which could generate accurate blood pressure differences between four limbs, provide a comprehensive evaluation of blood pressure and improve the accuracy of blood pressure for cardiovascular disease diagnosis $[2,4]$.

A blood pressure difference between arms has been associated with subclavian stenosis, peripheral artery disease, cardiovascular mortality and all-cause mortality $[1,8-11]$, meanwhile recent studies on inter-leg systolic blood pressure difference have added a new evidence to this concept [12-14]. The meta-analysis reported by Cao showed that inter-arm systolic blood pressure difference $\geq 15 \mathrm{mmHg}$ might help to predict increased cardiovascular mortality (HR 1.94, 95\% CI 1.12-3.35, P < 0.05) in the community populations [15]. However, the other meta-analysis reported by Singh showed that there was not statistically direct association of cardiovascular mortality with inter-arm systolic blood pressure difference of $10 \mathrm{mmHg}$ or more (OR 1.82; CI 0.68-4.88; $\mathrm{P}=0.23$ ), $15 \mathrm{mmHg}$ or more (OR 1.66; CI 0.68-4.07; $\mathrm{P}=0.27$ ), and inter-leg systolic blood pressure difference of $15 \mathrm{mmHg}$ or more (OR 1.97; CI 0.72-5.34; $\mathrm{P}=0.19$ ) [2]. Although the importance of blood pressure difference between arms or between legs is sometimes already recognized [1, 8-14], association of four limbs blood pressure differences with cardiovascular mortality and morbidity remains controversial.

Accordingly, this study aims to investigate the association of simultaneously measured four-limb blood pressures with cardiovascular function as the current non-invasive diagnostic method of cardiovascular disease in primary care.

\section{Methods}

\section{Subjects}

This study was approved by the Ethics Committee of Hospital in Beijing University of Technology, and College of Life Science and Bioengineering in Beijing University of Technology. All subjects gave written informed consent. From September 2015 to January 2016, staffs of Beijing University of Technology took part in comprehensive examinations of cardiovascular disease and its risk evaluation. Subjects with limb disability, hemiplegia, congenital heart disease, heart failure, and the history of artery intervention were excluded. Finally, 229 subjects (62 males, mean age, $63.50 \pm 11.13$ years; 167 females, mean age, $59.47 \pm 7.33$ years) were enrolled in this study.

\section{Four-limb blood pressure measurements}

Four-limb blood pressure was measured in an air-conditioned room at a temperature of $22-23{ }^{\circ} \mathrm{C}$ by using the VS-1500 blood pressure and pulse monitor device (Fukuda 
Company, Beijing, China). Trained technicians placed the blood pressure cuffs on both arms and both ankles and performed the measurements, after each subject had bared four limbs and taken 10-min rest in supine position. The device simultaneously and automatically measured the supine blood pressure of four limbs, and automatically calculated the ankle-brachial index (ABI) [ABI include right ankle-brachial index (RABI) and left ankle-brachial index (LABI)], and then stored the measurement data in a database.

Based on the systolic and diastolic blood pressure, we calculated the inter-arm and inter-ankle blood pressure differences as the absolute value of the difference between the right and left arm blood pressure and between the right and left ankle blood pressure, respectively. Pulse pressure (PP) was the absolute value of difference between systolic and diastolic blood pressure. Pulse pressure index (PPI) was calculated as the ratio of PP divided by systolic blood pressure. Mean arterial pressure (MAP) was two-thirds diastolic pressure plus one-third systolic pressure.

\section{Cardiovascular function measurements}

Cardiac functional parameters were also measured by using a cardiac hemodynamic detector device (Boundless Horizon Company, Shandong, China) in the supine position and in the same air-conditioned room after obtaining four limbs blood pressure. Before cardiovascular function measurement, each subject had bared abdomen and neck, stuck to electrode slices and taken 10-min rest in supine position. Trained technicians placed the red/black electrode holders on abdomen and neck, placed one yellow electrode holder on the fifth rib left anterior axillary line, respectively. The specific measurement positions were shown in Fig. 1. The device automatically measured the cardiac functional parameters, and then stored the measurement data in a database. Cardiovascular

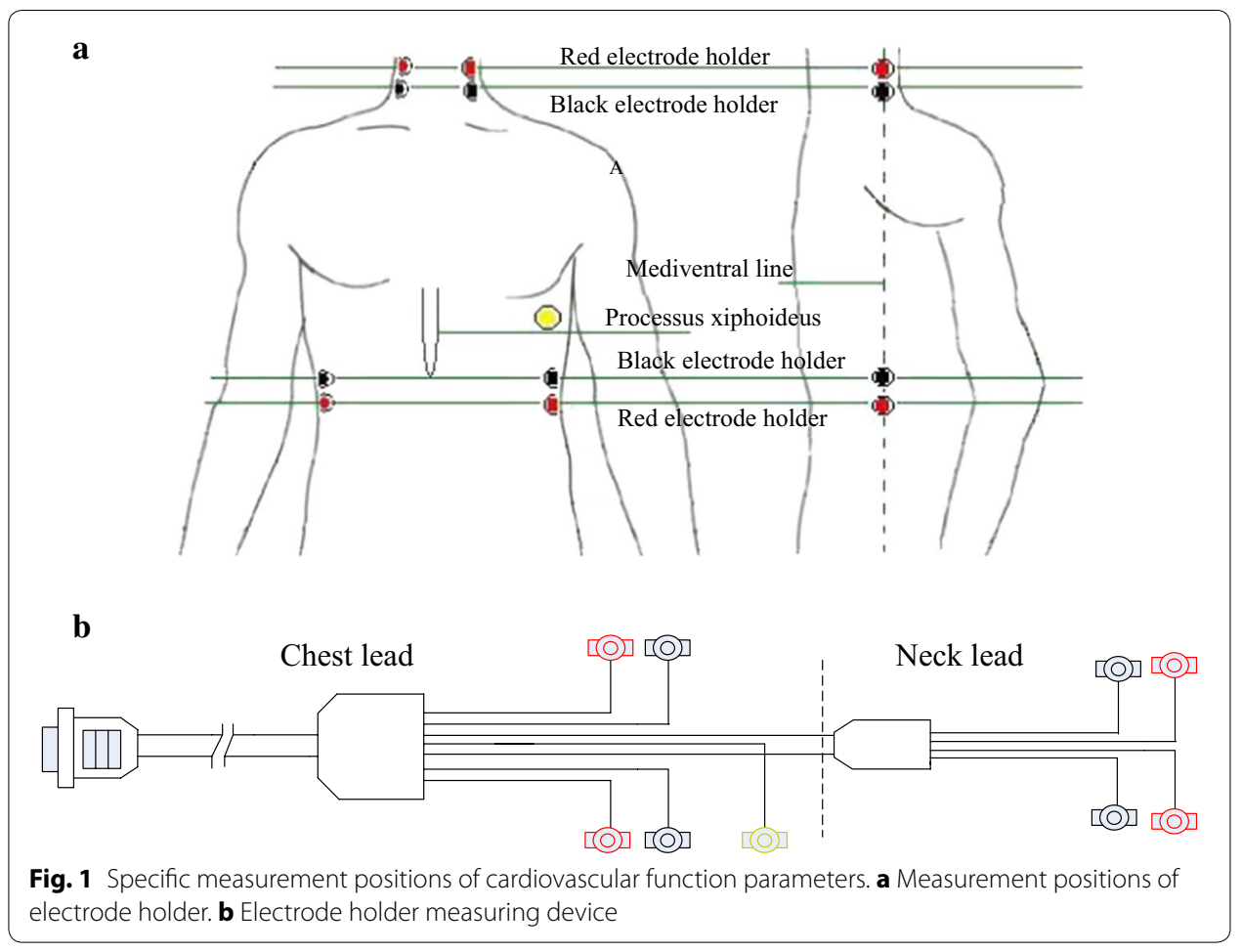


functional parameters related mainly to five parameters in this study: cardiac pump function, cardiac systolic, cardiac diastolic, cardiac efficiency and vascular elasticity.

Cardiac pump function parameters include cardiac output per minute $(\mathrm{CO})$, stroke volume (SV), cardiac index (CI), stroke volume index (SVI) and ejection fraction (EF). Cardiac systolic function parameters have function index of left ventricular (LFVI), index of contractility (IC) and heather index (HI). Cardiac diastolic function parameters have end diastolic volume (EDV) and left ventricular end diastolic pressure (LVEDP). Cardiac efficiency function parameters have stroke work (SW), cardiac work (CW), stroke work index (SWI) and cardiac work index (CWI). Vascular elasticity function parameters have aortic compliance (AC) and total peripheral resistance (TPR).

In addition, the observer also administered a standardized questionnaire to collect information of subjects on age, sex, height, weight, medical history, lifestyle, use of medications, drinking and smoking history. The body mass index (BMI) was calculated as the ratio of weight in kilograms divided by the square of height in meters.

\section{Statistical analysis}

Data were stored in Excel 2013 and statistically analyzed with SPSS15.0. Data were expressed as percentages and mean $\pm \mathrm{SD}$. The differences of inter-arm and inter-ankle were divide into five groups $(<5,5-9,10-14,15-19$ and $\geq 20)$, and $A B I$ were divide into three groups $(\leq 0.9,0.91-0.99, \geq 1.0)$. The differences between groups were checked by the analysis of variance for continuous variables or by Chi square test for categorical variables. Pearson correlation analysis was used to determine the correlation degree between cardiac functional parameters and four-limb blood pressure. Multiple linear regression analysis was used to determine the relationship between cardiac functional parameters and four-limb blood pressure. A difference was considered significant if the P value was less than 0.05 .

\section{Results}

\section{Baseline characteristics of subjects}

The mean age of the 229 subjects was $60.56 \pm 8.68$ years, 9 subjects were younger than 45 years, 31 subjects between 45 and 54 years, 136 subjects between 55 and 64 years, 39 subjects between 65 and 74 years, and 14 subjects were aged 75 years or older. Table 1 presents the clinical characteristics of the subjects by gender. The cardiovascular functional parameter difference in CI, EF, LFVI, IC, HI, EDV was significance between male and female $(\mathrm{P}<0.05)$. Also, independent-samples $\mathrm{T}$ test was performed between hypertension patients and the general population, and it was found that the differences of cardiovascular functional parameters as CI, SV, CO, SVI, EF, LFVI, IC, HI, LVEDP, EDV, AC and TPR were significant $(\mathrm{P}<0.05)$ between them. The mean values of these parameters in hypertension patients were lower than those of the general population except TPR.

\section{Pearson correlation analysis between four-limb blood pressures and cardiovascular functional parameters}

Pearson correlation analysis presents the correlation degree between four-limb blood pressures and cardiovascular functional parameters as shown in Table 1. Cardiac pump function parameters $(\mathrm{CO}, \mathrm{SV}, \mathrm{CI}, \mathrm{SVI}$, and $\mathrm{EF})$ have significant differences $(\mathrm{P}<0.05)$ 
Table 1 Baseline characteristics of the study participants

\begin{tabular}{|c|c|c|c|c|}
\hline \multicolumn{2}{|l|}{ Characteristics } & Male $(n=62)$ & Female $(n=167)$ & $\mathbf{P}$ \\
\hline \multicolumn{2}{|l|}{ Age, years } & $63.50 \pm 11.13$ & $59.47 \pm 7.33$ & 0.002 \\
\hline \multicolumn{2}{|c|}{ Body mass index, $\mathrm{kg} / \mathrm{m}^{2}$} & $24.54 \pm 3.15$ & $25.75 \pm 3.70$ & 0.023 \\
\hline \multicolumn{5}{|c|}{ Simultaneous four-limb BP measurement, $\mathrm{mmHg}$} \\
\hline \multirow[t]{2}{*}{ Left arm } & Systolic pressure (LARSP) & $136.69 \pm 19.01$ & $135.78 \pm 18.22$ & 0.740 \\
\hline & Diastolic pressure (LARDP) & $82.50 \pm 10.96$ & $81.02 \pm 10.28$ & 0.342 \\
\hline \multirow[t]{2}{*}{ Right arm } & Systolic pressure (RARSP) & $136.89 \pm 18.47$ & $135.78 \pm 18.58$ & 0.688 \\
\hline & Diastolic pressure (RARDP) & $83.21 \pm 11.87$ & $81.32 \pm 10.06$ & 0.230 \\
\hline \multirow[t]{2}{*}{ Left ankle } & Systolic pressure (LASP) & $151.48 \pm 26.19$ & $150.38 \pm 22.77$ & 0.754 \\
\hline & Diastolic pressure (LADP) & $79.82 \pm 10.87$ & $77.25 \pm 8.30$ & 0.057 \\
\hline \multirow[t]{2}{*}{ Right ankle } & Systolic pressure (RASP) & $150.45 \pm 25.93$ & $150.47 \pm 22.78$ & 0.997 \\
\hline & Diastolic pressure (RADP) & $77.05 \pm 11.50$ & $75.16 \pm 7.58$ & 0.150 \\
\hline \multicolumn{5}{|c|}{$\mathrm{BP}$ on the higher arm/ankle side of systolic pressure, $\mathrm{mmHg}$} \\
\hline \multirow[t]{5}{*}{ Arm } & Systolic pressure (HARSP) & $140.27 \pm 18.79$ & $139.03 \pm 18.44$ & 0.652 \\
\hline & Diastolic pressure (HARDP) & $83.94 \pm 11.56$ & $81.72 \pm 10.38$ & 0.166 \\
\hline & Pulse pressure (HARPP) & $56.34 \pm 14.19$ & $57.31 \pm 10.38$ & 0.647 \\
\hline & Pulse pressure index (HARPPI) & $0.40 \pm 0.06$ & $0.41 \pm 0.06$ & 0.299 \\
\hline & Mean arterial pressure (HARMAP) & $102.72 \pm 12.73$ & $100.03 \pm 11.85$ & 0.295 \\
\hline \multirow[t]{4}{*}{ Ankle } & Systolic pressure (HASP) & $154.50 \pm 25.99$ & $153.79 \pm 22.51$ & 0.839 \\
\hline & Diastolic pressure (HADP) & $80.02 \pm 11.81$ & $77.11 \pm 8.50$ & 0.041 \\
\hline & Pulse pressure (HAPP) & $74.48 \pm 18.27$ & $76.68 \pm 17.93$ & 0.414 \\
\hline & Pulse pressure index (HAPPI) & $0.48 \pm 0.07$ & $0.49 \pm 0.06$ & 0.046 \\
\hline \multicolumn{5}{|c|}{ Inter-arm BP difference, mmHg } \\
\hline Systolic pressure & mean $\pm S D$ & $6.97 \pm 7.66$ & $6.63 \pm 5.98$ & 0.725 \\
\hline Diastolic pressure & mean $\pm S D$ & $4.35 \pm 3.30$ & $3.95 \pm 3.84$ & 0.466 \\
\hline Systolic pressure & $\geq 10$ mmHg, n (\%) & $9(14.5)$ & $23(13.7)$ & 0.705 \\
\hline Systolic pressure & $\geq 15$ mmHg, n (\%) & $9(14.5)$ & $17(10.2)$ & 0.528 \\
\hline Diastolic pressure & $\geq 10$ mmHg, n (\%) & $3(4.8)$ & $7(4.1)$ & 0.362 \\
\hline Diastolic pressure & $\geq 15$ mmHg, n (\%) & $1(1.6)$ & $4(2.4)$ & 0.702 \\
\hline \multicolumn{5}{|c|}{ Inter-ankle BP difference, mmHg } \\
\hline Systolic pressure & mean $\pm S D$ & $7.06 \pm 7.87$ & $6.74 \pm 5.20$ & 0.715 \\
\hline Diastolic pressure & mean $\pm S D$ & $4.87 \pm 4.07$ & $4.11 \pm 3.48$ & 0.165 \\
\hline Systolic pressure & $\geq 10$ mmHg, n (\%) & $5(8.1)$ & $26(15.6)$ & 0.712 \\
\hline Systolic pressure & $\geq 15$ mmHg, $\mathrm{n}(\%)$ & $9(14.5)$ & $16(9.6)$ & 0.001 \\
\hline Diastolic pressure & $\geq 10$ mmHg, n (\%) & $4(6.5)$ & $18(10.8)$ & 0.054 \\
\hline Diastolic pressure & $\geq 15$ mmHg, n (\%) & $3(4.8)$ & $0(0)$ & - \\
\hline \multicolumn{5}{|c|}{ Arm-ankle BP difference, mmHg } \\
\hline L-ABI & mean $\pm S D$ & $1.08 \pm 0.15$ & $1.08 \pm 0.10$ & 0.979 \\
\hline $\mathrm{R}-\mathrm{ABI}$ & mean $\pm S D$ & $1.08 \pm 0.16$ & $1.08 \pm 0.09$ & 0.734 \\
\hline \multirow[t]{3}{*}{$L-A B \mid$} & $\leq 0.9, \mathrm{n}(\%)$ & $4(6.1)$ & $6(3.6)$ & 0.015 \\
\hline & $0.91-0.99$, n (\%) & $6(9.7)$ & $30(18.0)$ & 0.852 \\
\hline & $\geq 1.00, \mathrm{n}(\%)$ & $52(83.9)$ & $131(78.4)$ & 0.497 \\
\hline \multirow[t]{3}{*}{$\mathrm{R}-\mathrm{ABI}$} & $\leq 0.9, \mathrm{n}(\%)$ & $5(8.1)$ & $5(3.0)$ & 0.176 \\
\hline & $0.91-0.99$, n (\%) & $7(11.3)$ & $26(15.6)$ & 0.992 \\
\hline & $\geq 1.00, n(\%)$ & $50(80.6)$ & $136(81.4)$ & 0.251 \\
\hline \multicolumn{5}{|c|}{ Cardiac pump function } \\
\hline \multicolumn{2}{|l|}{$\mathrm{CO}$} & $5.27 \pm 1.16$ & $5.26 \pm 1.19$ & 0.969 \\
\hline \multicolumn{2}{|l|}{ SV } & $78.90 \pm 17.98$ & $76.81 \pm 18.19$ & 0.439 \\
\hline \multicolumn{2}{|l|}{$\mathrm{Cl}$} & $2.98 \pm 0.76$ & $3.23 \pm 0.82$ & 0.034 \\
\hline
\end{tabular}


Table 1 continued

\begin{tabular}{llll}
\hline Characteristics & Male $(\mathbf{n}=\mathbf{6 2})$ & Female $(\mathbf{n}=\mathbf{1 6 7})$ & $\mathbf{P}$ \\
\hline SVI & $44.69 \pm 11.84$ & $47.34 \pm 12.63$ & 0.152 \\
EF & $0.64 \pm 0.07$ & $0.69 \pm 0.07$ & 0.000 \\
Cardiac systolic function & & & \\
LFVI & $0.17 \pm 0.02$ & $0.16 \pm 0.01$ & 0.002 \\
IC & $0.05 \pm 0.01$ & $0.06 \pm 0.02$ & 0.000 \\
HI & $17.02 \pm 4.84$ & $22.03 \pm 6.83$ & 0.000 \\
Cardiac diastolic function & & & \\
EDV & $121.41 \pm 17.57$ & $110.23 \pm 18.14$ & 0.000 \\
LVEDP & $10.30 \pm 3.41$ & $9.46 \pm 2.98$ & 0.067 \\
Cardiac efficiency & & & \\
SW & $0.11 \pm 0.02$ & $0.10 \pm 0.02$ & 0.140 \\
CW & $7.09 \pm 1.55$ & $6.93 \pm 1.67$ & 0.511 \\
SWI & $0.06 \pm 0.01$ & $0.06 \pm 0.02$ & 0.303 \\
CWI & $4.00 \pm 0.96$ & $4.26 \pm 1.12$ & 0.109 \\
Vascular elasticity & & & \\
AC & $1.70 \pm 0.60$ & $1.74 \pm 0.83$ & 0.705 \\
TPR & $1598.87 \pm 453.21$ & $1558.99 \pm 408.93$ & 0.525 \\
\hline
\end{tabular}

and a negative correlation with age, BMI, HARSP, HARDP, HARPP, HARMAP, HASP, HADP, HAPP, RARSP, RARDP, LARSP, LARDP, RASP, RADP, LASP, and LADP. Cardiac systolic function parameters (IC and $\mathrm{HI})$ have significant differences $(\mathrm{P}<0.05)$ and a negative correlation with age, BMI, HARDP, HARMAP, HASP, HADP, LARDP, RADP, LASP, and LADP. Cardiac diastolic function parameters (EDV and LVEDP) have significant differences $(\mathrm{P}<0.05)$ and a negative correlation with BMI, HARSP, HARDP, HARMAP, HASP, HADP, HAPP, RARSP, RARDP, LARSP, LARDP, RASP, RADP, LASP, and LADP. Cardiac efficiency function parameters (SW, CW, SWI, and CWI) have significant differences $(\mathrm{P}<0.05)$ and a negative correlation with age and BMI, SWI also has significant differences $(\mathrm{P}<0.05)$ and a negative correlation with HARSP, HARDP, HARMAP, HASP, HADP, RARDP, LARSP, LARDP, RASP, RADP, LASP, and LADP. Vascular elasticity function parameter $(A C$ and TPR) have significant differences $(P<0.05)$ with age, BMI, HARSP, HARDP, HARPP, HARMAP, HASP, HADP, HAPP, RARSP, RARDP, LARSP, LARDP, RASP, RADP, LASP, and LADP, AC has a negative correlation with these parameters, and TPR has a position correlation with these parameters. Cardiovascular functional parameters have no significant differences with inter-arm blood pressure difference, inter-ankle blood pressure difference and ABI.

Multiple linear regression analysis between four-limb blood pressures and cardiovascular functional parameters

Multiple linear regression stepwise analysis presents the determinants of cardiovascular functional parameter as shown in Table 2. The independent factors negatively correlated with $\mathrm{CO}$ were found to be age, BMI and LADP $(\beta=-0.250,-0.332,-0.190$; all $\mathrm{P}<0.05)$. The independent factors negatively correlated with $\mathrm{SV}$ were found to be age, BMI, LADP and HARMAP $(\beta=-0.250,-0.318,-0.186,-0.157$; all $\mathrm{P}<0.05)$. The independent factors negatively correlated with $\mathrm{CI}$ were found to be age, BMI and LADP 
Table 2 Multiple linear regression stepwise analysis between four-limb blood pressure and cardiovascular functional parameters

\begin{tabular}{|c|c|c|c|c|c|}
\hline Dependent variable & $\mathbf{R}$ & Variable & $\beta$ & $P$ & $95 \% \mathrm{Cl}$ \\
\hline \multirow[t]{3}{*}{$\mathrm{CO}$} & 0.500 & Age & -0.250 & 0.000 & $(-0.050$ to -0.018$)$ \\
\hline & & BMI & -0.332 & 0.000 & $(-0.148$ to -0.070$)$ \\
\hline & & LADP & -0.190 & 0.002 & $(-0.040$ to -0.009$)$ \\
\hline \multirow[t]{4}{*}{ SV } & 0.586 & Age & -0.250 & 0.000 & $(-0.749$ to -0.292$)$ \\
\hline & & BMI & -0.318 & 0.000 & $(-2.161$ to -1.044$)$ \\
\hline & & HARMAP & -0.157 & 0.046 & $(-0.465$ to -0.004$)$ \\
\hline & & LADP & -0.186 & 0.016 & $(-0.670$ to -0.070$)$ \\
\hline \multirow[t]{3}{*}{$\mathrm{Cl}$} & 0.625 & Age & -0.240 & 0.000 & $(-0.032$ to -0.013$)$ \\
\hline & & $\mathrm{BMI}$ & -0.482 & 0.000 & $(-0.132$ to -0.085$)$ \\
\hline & & LADP & -0.204 & 0.000 & $(-0.028$ to -0.009$)$ \\
\hline \multirow[t]{4}{*}{ SVI } & 0.688 & Age & -0.255 & 0.000 & $(-0.504$ to -0.288$)$ \\
\hline & & BMI & -0.457 & 0.000 & $(-1.925$ to -1.240$)$ \\
\hline & & LARDP & -0.185 & 0.006 & $(-0.377$ to -0.063$)$ \\
\hline & & LADP & -0.169 & 0.013 & $(-0.411$ to -0.050$)$ \\
\hline \multirow[t]{4}{*}{ EF } & 0.591 & Age & -0.297 & 0.000 & $(-0.003$ to -0.002$)$ \\
\hline & & BMI & -0.252 & 0.000 & $(-0.007$ to -0.003$)$ \\
\hline & & LARDP & -0.173 & 0.021 & $(-0.002$ to 0.000$)$ \\
\hline & & LADP & -0.216 & 0.004 & $(-0.003$ to -0.001$)$ \\
\hline \multirow[t]{2}{*}{ LFVI } & 0.294 & Age & 0.186 & 0.005 & (0.000 to 0.001$)$ \\
\hline & & HARPP & -0.280 & 0.000 & (0.000 to 0.000 ) \\
\hline \multirow[t]{3}{*}{ IC } & 0.430 & Age & -0.313 & 0.000 & $(-0.001$ to 0.000$)$ \\
\hline & & BMl & -0.290 & 0.000 & $(-0.002$ to -0.001$)$ \\
\hline & & HARPPI & 0.148 & 0.016 & (0.007 to 0.071$)$ \\
\hline \multirow[t]{4}{*}{$\mathrm{HI}$} & 0.554 & Age & -0.363 & 0.000 & $(-0.367$ to -0.194$)$ \\
\hline & & BMI & -0.230 & 0.000 & $(-0.643$ to -0.218$)$ \\
\hline & & HARPPI & 0.161 & 0.005 & (5.143 to 28.907 ) \\
\hline & & LADP & -0.255 & 0.000 & $(-0.273$ to 0.0104$)$ \\
\hline \multirow[t]{3}{*}{ EDV } & 0.475 & Age & -0.148 & 0.014 & $(-0.572$ to -0.064$)$ \\
\hline & & BMI & -0.308 & 0.000 & $(-2.215$ to -0.979$)$ \\
\hline & & HARMAP & -0.240 & 0.000 & $(-0.557$ to -0.181$)$ \\
\hline \multirow[t]{3}{*}{ LVEDP } & 0.327 & BMI & -0.198 & 0.003 & $(-0.283$ to -0.061$)$ \\
\hline & & LASP & -0.224 & 0.001 & $(-0.046$ to -0.013$)$ \\
\hline & & ADBPD & 0.131 & 0.044 & (0.003 to 0.220 ) \\
\hline \multirow[t]{2}{*}{ SW } & 0.400 & Age & -0.203 & 0.001 & ( -0.001 to 0.000$)$ \\
\hline & & BMl & -0.344 & 0.000 & $(-0.003$ to -0.001$)$ \\
\hline \multirow[t]{4}{*}{$C W$} & 0.415 & Age & -0.178 & 0.004 & $(-0.056$ to -0.011$)$ \\
\hline & & BMI & -0.313 & 0.000 & $(-0.199$ to -0.086$)$ \\
\hline & & RARDP & 0.347 & 0.000 & (0.028 to 0.080$)$ \\
\hline & & LADP & -0.194 & 0.026 & $(-0.065$ to -0.004$)$ \\
\hline \multirow[t]{2}{*}{ SWI } & 0.544 & Age & -0.201 & 0.000 & $(-0.001$ to 0.000$)$ \\
\hline & & BMI & -0.504 & 0.000 & $(-0.003$ to -0.002$)$ \\
\hline \multirow[t]{5}{*}{ CWI } & 0.547 & Age & -0.211 & 0.000 & ( -0.041 to -0.012$)$ \\
\hline & & BMI & -0.484 & 0.000 & $(-0.180$ to -0.111$)$ \\
\hline & & RARSP & 0.184 & 0.027 & (0.001 to 0.020 ) \\
\hline & & LADP & -0.242 & 0.003 & $(-0.048$ to -0.010$)$ \\
\hline & & RADP & 0.209 & 0.020 & (0.003 to 0.039 ) \\
\hline \multirow[t]{3}{*}{$A C$} & 0.562 & Age & -0.167 & 0.004 & $(-0.025$ to -0.005$)$ \\
\hline & & BMI & -0.175 & 0.002 & $(-0.062$ to -0.014$)$ \\
\hline & & LARSP & -0.434 & 0.000 & $(-0.023$ to -0.005$)$ \\
\hline \multirow[t]{4}{*}{ TPR } & 0.644 & Age & 0.238 & 0.000 & (6.506 to 16.539 ) \\
\hline & & BMI & 0.296 & 0.000 & (22.357 to 46.836 ) \\
\hline & & HARMAP & 0.191 & 0.001 & (1.587 to 11.696$)$ \\
\hline & & LADP & 0.260 & 0.000 & (5.432 to 18.592 ) \\
\hline
\end{tabular}


$(\beta=-0.240,-0.482,-0.204$; all $\mathrm{P}<0.05)$. The independent factors negatively correlated with SVI were found to be age, BMI and LARDP $(\beta=-0.255,-0.457,-0.185$; all $\mathrm{P}<0.05)$. The independent factors negatively correlated with EF were found to be age, BMI, LARDP and LADP $(\beta=-0.297,-0.252,-0.173,-0.216$; all $\mathrm{P}<0.05)$. The independent factors negatively and positively correlated with LFVI were found to be HARPP $(\beta=-0.280 ; \mathrm{P}<0.05)$ and age $(\beta=0.186 ; \mathrm{P}<0.05)$ respectively. The independent factors negatively and positively correlated with IC were found to be age, BMI $(\beta=-0.313$, -0.290 ; all $\mathrm{P}<0.05)$ and HARPPI $(\beta=0.148 ; \mathrm{P}<0.05)$ respectively. The independent factors negatively and positively correlated with $\mathrm{HI}$ were found to be age, BMI, LADP $(\beta=-0.363,-0.230,-0.255$; all $\mathrm{P}<0.05)$ and HARPPI $(\beta=0.161 ; \mathrm{P}<0.05)$ respectively. The independent factors negatively correlated with EDV were found to be age, BMI and HARMAP $(\beta=-0.148,-0.308,-0.240$; all $\mathrm{P}<0.05)$. The independent factors negatively and positively correlated with LVEDP were found to be BMI, LASP $(\beta=-0.198$, -0.224 ; all $\mathrm{P}<0.05)$ and ADBPD $(\beta=0.131 ; \mathrm{P}<0.05)$ respectively. The independent factors negatively correlated with SW were found to be age and BMI $(\beta=-0.203,-0.344$; all $\mathrm{P}<0.05)$. The independent factors negatively and positively correlated with $C W$ were found to be age, BMI, LADP $(\beta=-0.178,-0.313,-0.194$; all $\mathrm{P}<0.05)$ and ADBPD $(\beta=0.131 ; \mathrm{P}<0.05)$ respectively. The independent factors negatively correlated with SWI were found to be age and BMI $(\beta=-0.201,-0.504$; all $\mathrm{P}<0.05)$. The independent factors negatively and positively correlated with CWI were found to be age, BMI, LADP $(\beta=-0.211,-0.484,-0.242 ;$ all $\mathrm{P}<0.05)$ and RARSP, RADP $(\beta=0.184,0.209 ; \mathrm{P}<0.05)$ respectively. The independent factors negatively correlated with $\mathrm{AC}$ were found to be age, BMI and LARSP $(\beta=-0.167,-0.175,-0.434$; all $\mathrm{P}<0.05)$. The independent factors positively correlated with TPR were found to be age, BMI, LADP and HARMAP $(\beta=0.238,0.296,0.191,0.260 ;$ all $\mathrm{P}<0.05)$.

\section{Variance analysis between four-limb blood pressure differences and cardiovascular functional parameters}

In additional, variance analysis was performed to check the difference among the cardiovascular functional parameters, four-limb blood pressure differences $(<5,5-9,10-14$, $15-19$ and $\geq 20)$ and ABI $(\leq 0.9,0.91-0.99, \geq 1.0)$. The distribution of four-limb blood pressure differences as shown in Fig. 2. There were 11.35, 4.37, 10.92, and 9.61\% of subjects with an inter-arm difference in systolic blood pressure of $>15 \mathrm{mmHg}$, inter-arm difference in diastolic blood pressure of $>10 \mathrm{mmHg}$, inter-ankle difference in systolic blood pressure of $>15 \mathrm{mmHg}$ and inter-ankle difference in diastolic blood pressure of $>10 \mathrm{mmHg}$, respectively. The mean distribution of cardiovascular functional parameters among four-limb blood pressure difference $(<5,5-9,10-14,15-19$ and $\geq 20)$ as shown in Figs. 3 and 4. Cardiovascular functional parameters (CI, SV, CO, SVI, EDV, TPR, SW, SWI and CWI) have significant differences $(\mathrm{P}<0.05)$ with inter-arm difference in systolic blood pressure between $\geq 10$ and $<10 \mathrm{mmHg}$. Cardiovascular functional parameters (EF, HI and TPR) have significant differences $(\mathrm{P}<0.05)$ with inter-ankle difference in systolic blood pressure between $\geq 15$ and $\geq 20 \mathrm{mmHg}$. Cardiovascular functional parameters (LFVI and AC) have significant differences $(\mathrm{P}<0.05)$ with inter-ankle difference in systolic blood pressure between $\geq 15$ and $<10 \mathrm{mmHg}$. CI, CO, LVEDP, CW, CWI have significant differences $(\mathrm{P}<0.05)$ with $\mathrm{RABI}$ between $\leq 0.9$ and $\geq 1.0$. 


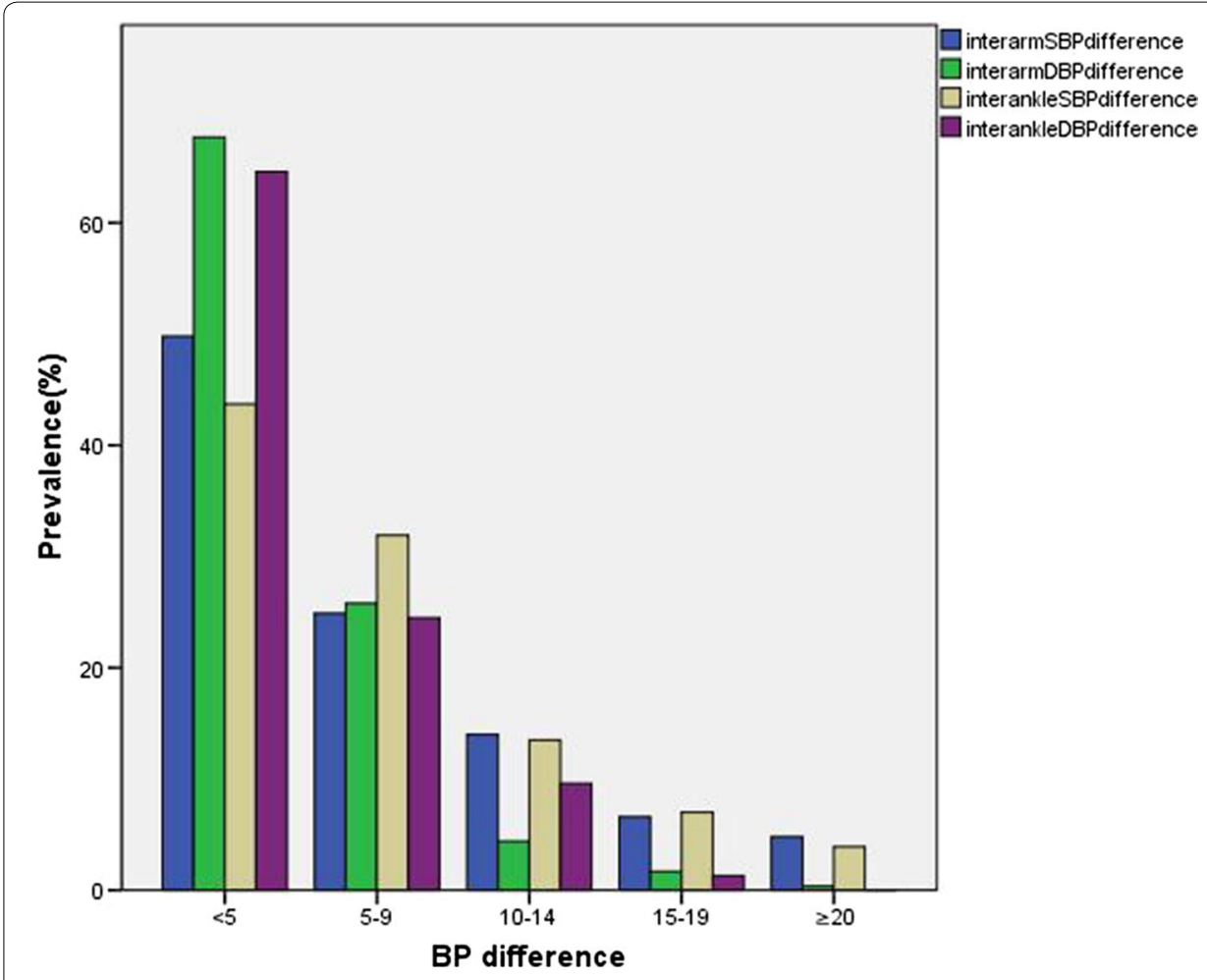

Fig. 2 The distribution of four-limb blood pressure difference in the subjects

\section{Analysis between four-limb blood pressures and cardiovascular functional parameters} in subgroup

Since cardiovascular function has been associated with hypertension, we also performed a subgroup analysis after excluding 99 hypertension patients. After Pearson correlation analysis in subgroup, we found that a part of blood pressure parameters correlation with cardiovascular functional parameters disappeared, and the correlation coefficient reduced. In addition, after analysis of variance in subgroup, we also found that cardiovascular functional parameters $(\mathrm{SV}, \mathrm{EDV}$ and $\mathrm{SW})$ have significant differences $(\mathrm{P}<0.05)$ with inter-arm difference in systolic blood pressure between $\geq 10$ and $\geq 15 \mathrm{mmHg}$, and cardiovascular functional parameters (CI, CO, TPR, CWI and HI) have significant differences $(\mathrm{P}<0.05)$ with $\mathrm{RABI}$ between $\leq 0.9$ and $\geq 1.0$.

\section{Discussion}

In this cross-sectional study, by using a simultaneous measurement technique, the association between four-limb blood pressure and cardiovascular function and related risk factors was evaluated. Cardiovascular functional parameters illustrated the cardiac pump function, cardiac systolic, cardiac diastolic, cardiac efficiency and vascular elasticity. Thus, this study has more systematicness and pertinence than previous studies. This study suggested that cardiovascular functional parameters (CO, SV, CI, SVI, EF, IC, HI, EDV, LVEDP, SWI, AC and TPR) have all a significant difference with HARDP, HARMAP, HASP, HADP, LARDP, RADP, LASP, and LADP, while there was a negative correlation between them except TPR. Meanwhile, the determinants of cardiac functional 


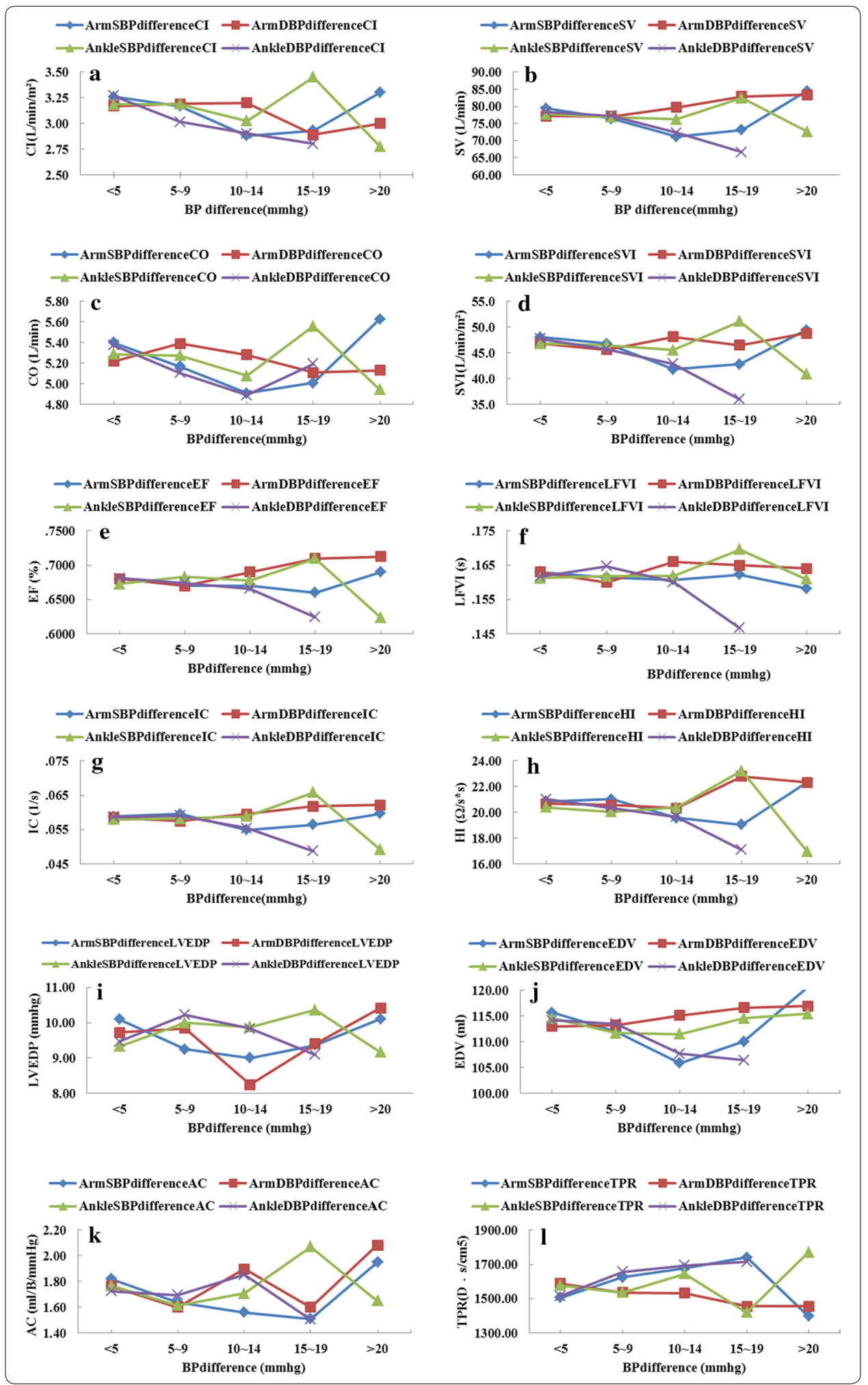

parameter were age, BMI, LADP, HARMAP LARDP, HARPPI ADBPD, RARSP, RADP and LARSP, while the TPR was positively correlated with age, BMI, LADP and HARMAP. 
(See figure on prrevious page.)

Fig. 3 The mean distribution of cardiovascular functional parameters among four-limb blood pressure difference in this study subjects. a Mean distribution of $\mathrm{Cl}$ among four-limb blood pressure differences. $\mathbf{b}$ Mean distribution of SV among four-limb blood pressure differences. c Mean distribution of CO among four-limb blood pressure differences. $\mathbf{d}$ Mean distribution of SVI among four-limb blood pressure differences. e Mean distribution of EF among four-limb blood pressure differences. $\mathbf{f}$ Mean distribution of $\mathrm{LFVI}$ among four-limb blood pressure differences. $\mathbf{g}$ Mean distribution of IC among four-limb blood pressure differences. $\mathbf{h}$ Mean distribution of $\mathrm{HI}$ among four-limb blood pressure differences. i Mean distribution of LVEDP among four-limb blood pressure differences. $\mathbf{j}$ Mean distribution of EDV among four-limb blood pressure differences. $\mathbf{k}$ Mean distribution of AC among four-limb blood pressure differences. I Mean distribution of TPR among four-limb blood pressure differences

Previous studies demonstrated that population aging has become the uncontrolled risk factor of cardiovascular disease [16-18]. It is a physiology problem that the effect between blood pressure and cardiovascular function is mutual. The cardiovascular function decreased gradually with age, especially arteries can produce physiological degeneration. The thickening of vessels wall, the decrease or even rupture and calcification of elastic fibers, the increase of peripheral resistance, the decrease of blood vessel compliance, all these factors will result in the systolic blood pressure and diastolic blood pressure increasing with age. In addition, it is a fluid mechanics problem that different arteries away from heart have different resistance and pressure. According to the Poiseuille's law, brachial artery resistance is relatively small and the blood pressure is low because heart is close to the upper limb, while the phenomenon of the ankle artery is in contrast. Hence blood pressures in four limbs are different. In addition, the distance from the heart affects pressure wave propagation and reflection because of the geometry tapper and elasticity tapper, and augments the pressure of peripheral vascular compared with that of upper limb.

Previous studies have reported that inter-arm or inter-ankle blood pressure difference predicted cardiovascular mortality $[1,2,8-13,15]$. These results suggested that the

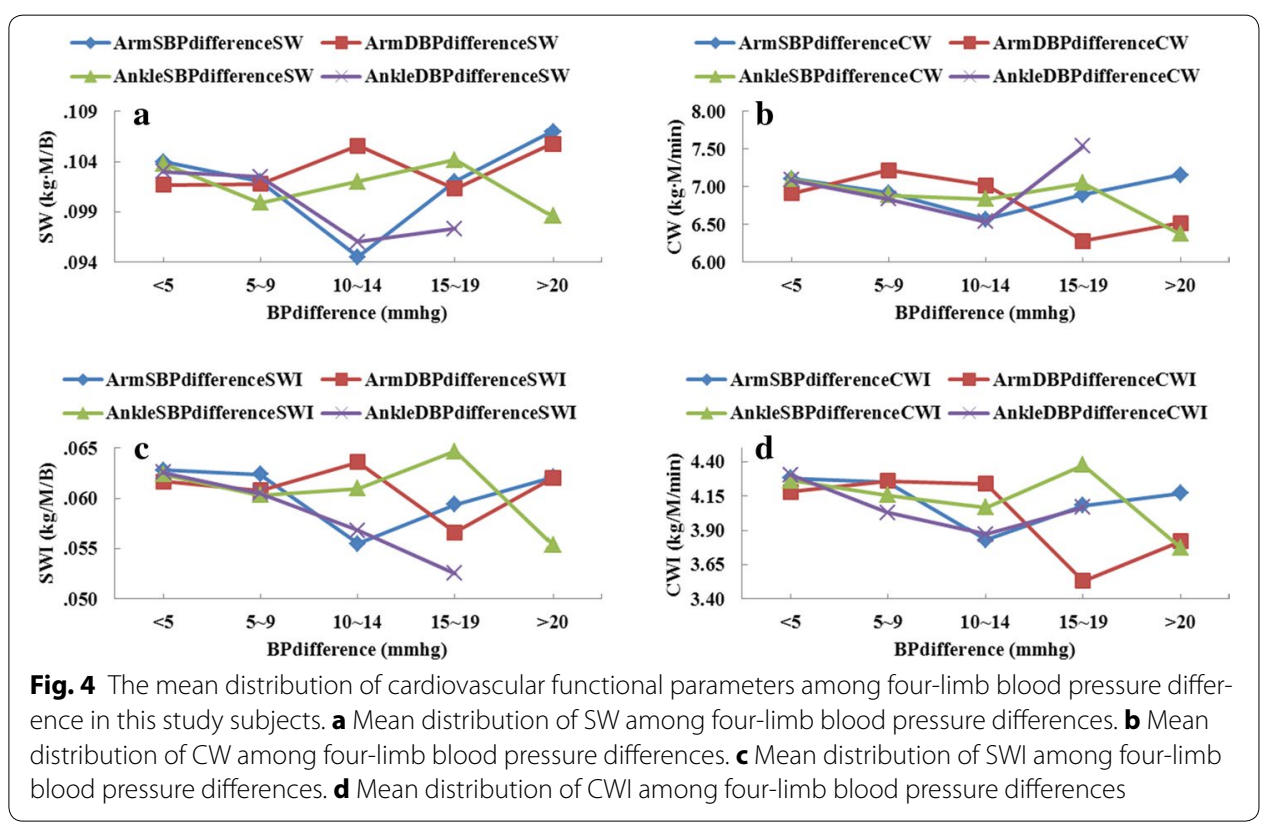


simultaneous measurement of four-limb blood pressure is needed to improve diagnostic accuracy between cardiovascular disease and blood pressure difference [2-5]. The present study demonstrated the significant correlation between cardiovascular functional parameters and four-limb blood pressure, while cardiovascular functional parameters had no significant differences with inter-arm blood pressure difference, inter-ankle blood pressure difference and ABI. However, the mean plots of cardiovascular functional parameters present obvious change trend in four-limb systolic blood pressure difference and diastolic blood pressure difference $\geq 10$ or $\geq 15 \mathrm{mmHg}$. These results were different form previous studies. Verberk et al. [19] reported that the prevalence of inter-arm difference in systolic blood pressure of $10 \mathrm{mmHg}$ or more was roughly doubled when diagnosis measurements method used a sequential approach, or used manual approach rather than automated measurements approach. Thus, simultaneous measurement of four-limb blood pressure and calculation of four-limb blood pressure difference may be helpful and necessary in evaluating the heart function and predicting patients with cardiovascular disease. Further study, the subgroup analysis showed that the predictive value of four limbs blood pressure for cardiovascular function. Subgroup analysis found that a part of cardiovascular functional parameter has still significant differences $(\mathrm{P}<0.05)$ with inter-arm difference in systolic blood pressure between $\geq 10$ and $\geq 15 \mathrm{mmHg}$, and with RABI between $\leq 0.9$ and $\geq 1.0$. However, the exact reason is unclear now, hypertension is the influence factors of cardiovascular function parameters, and four-limb blood pressure differences are also applicable to diagnose hypertensive patients. As mentioned above, four limbs blood pressures were not only influence factors of cardiovascular function parameters, but a predictor for cardiovascular disease, evaluating cardiovascular function parameters was important in clinical practice and epidemiological studies. In addition, the better way for cardiovascular function parameters was simultaneous blood pressures for four limbs.

A clinical device, the VS-1500 blood pressure and pulse monitor device (Fukuda Company, Beijing, China), has been developed to automatically and simultaneously measure blood pressure in four limbs, and the measurement can be easily obtained. The similar device was reported by previous studies, for example, VP-1000 ABI-form device (Colin Co. Ltd., Komaki, Japan) and VP-1000 device (Omron, Kyoto, Japan) were used to automatically and simultaneously measure four limbs' blood pressures. The validation in measurement technology of device (Boundless Horizon Company, Shandong, China) might be prone for measurement errors, especially in multinomial detection of cardiac function parameters rather than single detection. Although it could not give very precise measurements for the clinical value of cardiac function parameters, it can provide objective evaluation of health in the early stage of cardiovascular diseases. Thus, these devices can be applied for the epidemiological evaluation between four limbs' blood pressures and cardiac function parameters.

In this study, by using a simultaneous and noninvasive measurement technique, we measured four limbs blood pressures. But this technique was not a popular one to measure blood pressure in daily clinical practice. Hence, although four limbs blood pressure with simultaneous measurement could improve the predictive value for cardiovascular disease, our results might be changed if daily clinical measurement was used. In addition, the subjects were mainly from retired people, whose health care consciousness is 
better than the serving officer. The factors of smoking, drinking, salting and movement have no significant difference in this study subjects. Hence, the clinical utility of this study may be limited in community people.

\title{
Conclusion
}

LADP, HARMAP, LARDP, and RADP were all significantly correlated with cardiovascular functional parameter. Age and body mass index are all the major risk factors for cardiovascular function parameters. In addition, a part of cardiovascular functional parameter is associated with inter-arm difference in systolic blood $\geq 10 \mathrm{mmHg}$, interankle difference in systolic blood pressure $\geq 15 \mathrm{mmHg}$ and RABI $\leq 0.9$, while these differences still exist after excluding 99 hypertension patients. Hence, simultaneous measurement of four-limb blood pressures has become feasible and useful approach to the current non-invasive method of cardiovascular disease in primary care.

\begin{abstract}
Abbreviations
CO: cardiac output per minute; Cl: cardiac index; SV: stroke volume; SVI: stroke volume index; EF: ejection fraction; LFVI: function index of left ventricular; IC: index of contractility; HI: heather index; EDV: end diastolic volume; SW: stroke work; CW: cardiac work; SWI: stroke work index; CWI: cardiac work index; AC: aortic compliance; TPR: total peripheral resistance; HR: heart rate; SBP: systolic blood pressure; LARSP: left arm systolic pressure; LARDP: left arm diastolic pressure; RARSP: right arm systolic pressure; RARDP: right arm diastolic pressure; LASP: left ankle systolic pressure; LVEDP: left ventricular end diastolic pressure; LADP: left ankle diastolic pressure; RASP: right ankle systolic pressure; RADP: right ankle diastolic pressure; HARSP: high arm systolic pressure; HARDP: high arm diastolic pressure; HARPP: high arm pulse pressure; HARPPI: high arm pulse pressure index; HASP: high ankle systolic pressure; HADP: high ankle diastolic pressure; HAPP: high ankle pulse pressure; HAPPI: high ankle pulse pressure index; $A B I$ : ankle brachial index; RABl: right ankle brachial index; LABI: left ankle brachial index; PP: pulse pressure; PPI: pulse pressure index; MAP: mean arterial pressure; BMI: body mass index; HARMA: high arm mean arterial pressure.
\end{abstract}

\section{Declarations}

Authors' contributions

AQ was responsible for the guidance of experiment scheme design, collection and statistical analysis of clinical data, review and revision of the manuscript. XS was responsible for the overall design of the experiment, the implementation of the clinical data collection and statistical analysis, writing and editing of manuscript. GL was responsible for clinical data collection and the questionnaire survey. ZC was responsible for the guiding the clinical work and the rationality of medical statistical analysis, and proposed the opinions for the feasibility of medical experiments. All authors (1) have made substantial contributions to acquisition of clinical data, or experimental design, or analysis and interpretation of data; (2) have been involved in drafting the manuscript or revising it critically for important intellectual content; and (3) have given final approval of the version to be published. Each author has participated sufficiently in the work to take public responsibility for appropriate portions of the content. All authors read and approved the final manuscript.

\section{Author details}

${ }^{1}$ College of Life Science and Bioengineering, Beijing University of Technology, No.100, Pingleyuan, Chaoyang District, Beijing, China. ${ }^{2}$ School Hospital, Beijing University of Technology, No.100, Pingleyuan, Chaoyang District, Beijing, China.

\section{Acknowledgements}

We would like to acknowledge the support of the School Hospital in Beijing University of Technology (Beijing, China), where the fieldwork and measurement took place. This work was supported by National Natural Science Foundation of China (81171107, 11472023).

\section{Competing interests}

The authors declare that they have no competing interests.

\section{About this supplement}

This article has been published as part of BioMedical Engineering OnLine Volume 15 Supplement 2, 2016. Computational and experimental methods for biological research: cardiovascular diseases and beyond. The full contents of the supplement are available online http://biomedical-engineering-online.biomedcentral.com/articles/supplements/ volume-15-supplement-2.

\section{Availability of data and materials}

The data and materials in this paper can be shared.

\section{Funding}

Publication charges for this article have been funded by National Natural Science Foundation of China (81171107, 11472023)

Published: 28 December 2016 
References

1. Clark CE, Taylor RS, Shore AC. Inter arm blood pressure difference and vascular disease —authors' reply. Lancet. 2012;380(9836):24-5.

2. Singh S, Sethi A, Singh M, Khosla K, Grewal N, Khosla S. Simultaneously measured inter-arm and inter-leg systolic blood pressure differences and cardiovascular risk stratification: a systemic review and meta-analysis. J Am Soc Hypertens. 2015;9(8):640-50.

3. O'Shea J, Murphy M. Ambulatory blood pressure monitoring: which arm? J Hum Hypertens. 2000;14:227-30.

4. van der Hoeven NV, Lodestijn S, Nanninga S, van Montfrans GA, van den Born BJ. Simultaneous compared with sequential blood pressure measurement results in smaller inter-arm blood pressure differences. J Clin Hypertens. 2013;15(11):839-44

5. Verberk WJ, Kessels AGH, Thien T. Blood pressure measurement method and inter-arm differences: a meta-analysis. Am J Hypertens. 2011;24(11):1201-8.

6. Charmoy A, Würzner G, Ruffieux C, Hasler C, Cachat F, Waeber B, Burnier M. Reactive rise in blood pressure upon cuff inflation: cuff inflation at the arm causes a greater rise in pressure than at the wrist in hypertensive patients. Blood Press Monit. 2007;12(5):275-80.

7. Cortez-Cooper MY, Supak JA, Tanaka H. A new device for automatic measurements of arterial stiffness and anklebrachial index. Am J Cardiol. 2003;91(12):1519-22.

8. Clark CE, Taylor RS, Shore AC, Ukoumunne OC, Campbell JL. Association of a difference in systolic blood pressure between arms with vascular disease and mortality: a systematic review and meta-analysis. Lancet. 2012:379(9819):905-14

9. Clark CE, Campbell JL, Powell RJ. The interarm blood pressure difference as predictor of cardiovascular events in patients with hypertension in primary care: cohort study. J Hum Hypertens. 2007;21 (8):633-8.

10. Clark CE, Campbell JL, Powell RJ, Thompson JF. The interarm blood pressure difference and peripheral vascular disease: cross-sectional study. Fam Pract. 2007;24(5):420-6.

11. Cao K, Xu J, Sun H, Li P, Li J, Cheng X, Su H. The variability of ankle-arm blood pressure difference and ankle-brachial index in treated hypertensive patients. J Am Soc Hypertens. 2014;8(10):693-8.

12. Sheng CS, Liu M, Zeng WF, Huang QF, Li Y, Wang JG. Four-limb blood pressure as predictors of mortality in elderly Chinese. Hypertension. 2013;61(6):1155-60.

13. Chen SC, Chang JM, Tsai YC, Tsai JC, Su HM, Hwang SJ, Chen HC. Association of interleg BP difference with overall and cardiovascular mortality in hemodialysis. Clin J Am Soc Nephrol. 2012;7(10):1646-53.

14. Su HM, Lin TH, Hsu PC, Lee WH, Chu CY, Chen SC, Lee CS, Voon WC, Lai WT, Sheu SH. Association of interankle systolic blood pressure difference with peripheral vascular disease and left ventricular mass index. Am J Hypertens. 2014;27(1):32-7.

15. Cao K, Xu J, Shangguan Q, Hu W, Li P, Cheng X, Su H. Association of an inter-arm systolic blood pressure difference with all-cause and cardiovascular mortality: an updated meta-analysis of cohort studies. Int J Cardiol. 2015;189:211-9.

16. Dahlöf B. Cardiovascular disease risk factors: epidemiology and risk assessment. Am J Cardiol. 2010;105(1):3A-9A.

17. Ohira T, Iso H. Cardiovascular disease epidemiology in Asia. Circ J. 2013;77(7):1646-52.

18. Yang F, Qian D, Hu D, Hou MY, Chen S, Wang P, He L, Cai XZ, Feng ZK, Li XT, Xu JW, Zhong Q, Fan N. Prevalence of cardiovascular disease risk factor clustering in Chinese adults. Clin Trials Regul Sci Cardiol. 2016;15:1-6.

19. Verberk WJ, Kessels AGH, Thien T. Blood pressure measurement method and inter-arm differences: a meta-analysis. Am J Hypertens. 2011;24(11):201-1208.

Submit your next manuscript to BioMed Central and we will help you at every step:

- We accept pre-submission inquiries

- Our selector tool helps you to find the most relevant journal

- We provide round the clock customer support

- Convenient online submission

- Thorough peer review

- Inclusion in PubMed and all major indexing services

- Maximum visibility for your research

Submit your manuscript at www.biomedcentral com/submit 